\section{Sexual Violence towards Men: Sexual Violence Judging from Individual Factors of Victims}

\section{Tiara Diah Sosialita}

Fakultas Psikologi Universitas Airlangga, Surabaya. email : tiarasosialita@psikologi.unair.ac.id
Journal PSIKODIMENSIA

Volume 18, No. 1, Januari - Juni 2019

ISSN cetak : 1411-6073

ISSN online : 2579-6321

DOI 10.24167/psidim.v18i1.1773

\begin{abstract}
This study aims to explore the gender characteristics of the victims of sexual violence, so thatcomprehensive understanding about determinants of sexual violence can be obtained. Gender characteristics allow society to evaluate gender as part of their social role that is devised and related to particular public view that men are seen as an individual with more physical strength and responsibility than women in many various contexts. This study involved five men as victims of sexual violence whom experienced it by their partner in context of intimate relationship. Data collecting used Bem Sex Role Inventory (BSRI) questionnaire within in-depth interview. Result of this study was useful to provide a comprehensive description of mental dynamics according to the occurence of sexual violence. An understanding of sexual violence predictors was expected to reveal the phenomena of sexual violence towards men whereas lack of awareness in our society. Thus, considering the mental dynamics of sexual violence victim was headed us to be able to repeal the stigma related men and masculinity term. Result also revealed that sexual violence have been affected their identity and sexual activities. As the fact about this study, the existence of support system around them was an important help for them to deal and heal their conditon.
\end{abstract}

Keywords: Men, Sexual violence, violence.

\section{INTRODUCTION}

Sexual violence occurs in any place and anytime regardless who was the victim or who was the perpetrator. However, sexual violence is more common than few well-publicized cases would suggest. Research data indicate that sexual violence is widespread in the workplace, educational institutions, even in the street. Sexual violence is defined as unwelcome verbal or physical conduct of a sexual nature, and can range from unwanted flirtatious remarks to unwanted sexual advances, sexual assault, and coercion of sexual activity.

In Indonesia, recent studies that focus on sexual violence are required to reach an completed understanding about sexual violence phenomena. The number of these cases in Indonesia is increasing for women and children, but for male victims there is no clear and definite data that society can seen. Eventhough if we are seen from gender, sexual violence is more experienced by women reach $87 \%$, but it is also known that $13 \%$ of men become victims of sexual violence. Data of Komnas Perempuan shows that in 2014, there were 4.475 cases of sexual violence against women, in 2015 there were 6.499 cases, and in 2016 there were 5.785 cases (Komnas Perempuan, 2018).

Based on the incidents that happened, so that the existence of sexual violence should be our concern. Our society should be understand about sexual violence wherefore significant impact on physical and mental health ofthe victim (Van Niekerk \& Ryzgula, 
2010). In addition, a greater impact could threaten male victims accordance to prior studies that found that male victims are more likely experienced physical or psychological distress, even mental health problems than women (Brennan, 2012).

In Indonesia, phenomena of sexual violence often found in urban areas. As a victim, men have had bad experience for several time thus far they still struggle to overcome negative emotions. One of survivor revealed that his partner did sexual violence as long as they were in relationship. As a victim, he fought hard to overcome his trauma before decided to get professional help. Even it had been passed, he still experience negative feelings when his memories of sexual violence had been triggered. These conditions are indicated by the result of initial interviews with several men who were victims of sexual violence.

“... yes, first time we met in 2010 , end of 2010 we began dating. We dated for three years. I was with her [exgirlfriend] until 2013 when I finally realized that this condition must be stopped. Since I had our three years relationship before broke up, she [exgirlfriend] got mad if I refused for having sex. I felt dirty, umm... that was my first time for having sex, yes... and dating. Longer we were in relationship, frequency and intensity were incereasing. You could say extremes. Yes, if I could say... she was mad, crazy! When we were in public area, for instance, when we gathered with friends or in public place like malls, she even hold my sensitive areas. Yes, it was embarrassing. I always got angry when I remembered it. I realized that I had struggled for long time to forget [sexual violence], but it had been a part of my past that I will always carry on. Finally, recently two years ago I just started to seek professional counseling. I want move on." (AGJ, 28 years old)
Other survivor felt depressed because of his situation. Having sexual violence made him feel regret and angry, however he could not prevent to be happened. He had made an effort to stop sexual violence from his partner, but he afraid if his partner will spread disgraces to public. He do not want his family and friends to know.

"First we met then interacted, she was just like other girls. She like an innocent girl so... umm, even nobody will ever think she can do it [sexual violence]. No one. At first, because I think both of us are innocent, so yes... umm, initially we just want to try it. But more we did it, honestly I am afraid, ya it just like a feeling like she is going to tell around public about our sexual experience, aspecially to my parents. I am so worried. It's like [sexual intercourse] binds us and I have to accept it. This year, in early January [2017] we stay due to overnight, emm ... in lasy year [October 2016] was first time we did sex. After that, from this January, she forced me everytime we were together. She asked for sex and it was not common ... not normal. She hurt [pull harshly, hit, force-bite, and so forth]. Yes, it was different from the beginning. Getting here I feel that she is not a good person, but I am afraid to ask directly. Just like regretful feeling that it was my fault to commit a realtionship with her so that i'm feeling depressed now." (BA, 22 years old)

These statements is supported by a few researches that has been done in developing countries revealed $5-10 \%$ of men experience sexual violence in childhood. In many studies involving men in several developing countries, the percentage of men who were being victims of sexual violence range from $3.6 \%$ in Namibia, $13.4 \%$ in Republic of Tanzania, and 20\% in Peru. Researches show that sexual violence occurs in both developed and developing countries as evidence that violence could occur 
anywhere. Statistic data revealed that men could get violence in educational institutions, workplaces, homes, prisons, and even on the highway (Weiss, 2010). Researchers believe that prevalence of sexual violence towards men is very huge, but unlike women, men are more reluctant to report it.

Reluctance to report is greater if sexual violenece occurs in the context of interpersonal relationships both married and dating. A study showed findings that sexual violence in domestic relationship occurs in uncommon rate all over the world (Bergman, et al., 2002). The fact that $23 \%$ of sexual violence by spouse occurred in United Kingdom show that they as victims received sexual violence throughout their life. Similarly, it also occurred in Mexico (23\%), Nicaragua (21.7\%), Peru (22.5\%), Zimbabwe (25\%), Canada (8\%), Finland (14.2\%), Switzerland (5.9\%), and the United States $(7.7 \%)$. In Indonesia particularly in Central Java, there were 765 victims of sexual violence during 1999-2000 but did not report their cases. This finding could be said that men are like women in sexual violence case, tend to speak it up.

In men, reluctance for reporting sexual violence because they worry about the stigma of gender roles in society that men shoull not take themselves at term of embarrassment, withdrawal, self-harm behavior, depression, sleep disturbances, hostility, alcohol abuse, and even suicidal behavior. In addition, sexual violence also affects identity and sexual activity of survivors after they experienced it. Tendency of being gay if the perpetrator was also man brings an anxiety and fear, eventhough if the perpetrator was different gender so their masculinity could be treathened (Kenny, et al., 2011). This also be the reason to avoid new relationship with other person. Their condition may get worse when they doubt to open themselves up their sexual experience for getting professional help. During this time, survivors of sexual violence felt that have not anyone to support them. They kept their bad experiences should not be shared to others.

"Yes ... ummm, nobody know what I'm going through, what's going on for several years. I feel alone. Lonely. Yes, absolutely cannot share to anyone. I feel like... what people think? What do they they think about me? They must think that I am bad, right?" (OS, 25 years old)

"My parents, my brother ... I'm not sure, I think they are good parents. I have friends .. few friends but I socialize, I hang out with people around me. But if I told about my experience, I worried they will support me. Yes, because what I experienced is bad. I do not..., umm, there is no courage to share my story." (DMS, 33 years old)

"I feel safe and comfortable when I share my experienced to whom I don't know in personal like my psychogist who handles me. I prefer to tell my story to someone who are not familiar and close to me." (MH, 35 years old)

Understanding sexual violence cases by looking at the statistical number is considered as an unsatisfaction because this phenomenon have not blowed up. Victims of sexual violence have reluctancy to report it, particularly in male survivors. Cases of sexual are very rarely reported despite of the fact is widely occurred because of gender construction in society (Mahugu, et al., 2013). Ideas of masculinity include physical strength, men is controller, and have sexual attention more than women. Embarrassment plays vital role in determining whether to report or not, both in men and women. There is greater reluctance in men to report sexual violence than women, whereas it leaves huge impact on physical, menttal, even sexual consequences (Holzbauer \& Conrad, 
2010). Brennan (2012) reveals that the reasons for men to keep their sexual violence experiences and avoid to seek professional help because of embarrassment, fear, and doubt.

Looking at the phenomenon that sexual violence leaves profound impact of physical, psychological, emotional, and social into survivor life, so that a good understanding about individual factors of the victim becomes essential and important. Therefore, people around them could provide support so that they are able to cope with their suffering. This study focuses on how individual factors play vital role in the occurrance of sexual violence, particularly male as a victim. Unit of analysis of this research is occurrence of sexual violence in male victims as participants.

\section{METHOD}

This research used purposive and non-random sampling technique. Participants met criteria of: 1) early adulthood men (age range of 20-40 years old) who had been experienced sexual violence by intimate partner at least for six months; 2) had been gotten examination by primary health care personnels; 3) getting psychological help from professional; 4) domicile in Surabaya; 5) level of education at least graduate from Senior High School; 6) experiencing both physical and psychological suffering; 7) could be categorized as survivor.

Participants then were asked to complete questionnaire, interviews, and follow-up counseling if needed. Interview related to sexual violence experienced by each participants was conducted by researcher. Informed consent was given to potential participants who met the criteria and willing to be involved in this research.

Participants were underwent advanced assessment by the form of psychological test series to assess their cognitive, affective, and motivational aspects. In addition, in-depth interview related to BSRI questionnaire were done. The following data that gathered include:

1. What kind of sexual experience that the participant accepted from the partner and how does the participant interpret it?

2. How about the impact of sexual violence on the participant and what kind of coping strategy is used by the participant?

3. What are the factors that facilitate and prevent to report sexual violence experiences?

4. What are the individual factors that play vital role in the occurrence of sexual violence?

\section{RESULT}

The result section of this research include the effect of demographic factors, sexual violence experiences and its impact on participants, coping strategy that had been chosen, facilitative and preventtive factors, and the individual factors as the vital role in the occurrence of sexual violence.

First, from five participants, two participants were 20-25 years old and three participants were 26-35 years old. Four participants are Javanese and the rest is Chinese. All participants are domiciled in Surabaya, East Java. There are varying levels of education that ranging from high school to Master degree. Two participants are still having relationship with their partners who do sexual violence to them, while three other participants finished their relationship.

Results showed that almost all participants $(n=4)$ had experienced sexual abuse during childhood by people around them. All participants admitted that they shared experiences of sexual violence only to those they trusted. In 
this case, participants feel comfortable to open their story to the professionals. Ironically, they did not want their families or friends to know their experience of sexual violence.

The truth is sexual violence gives extreme emotional and psychological impact to all participants. Four out of five participants admitted that they had depression and post-traumatic stress disorder. A participant admitted that he even tried to commit suicide. All participants interpret that their sexual violence experience is an unpleasant incident. They feel ashamed on those experiences, feel guilty, and evaluate it as his fault. Those feelings develop unworthy feeling. Impact of sexual violence is still felt by all participants until now, eventhough they begin to open up and seek help from professionals.

Participants explain that they spent a long time and huge effort to decide found out professional help because of confusion and embarrassment of their experiences. Participants doubt that other people could help him and worry that his sexual violence experiences will spread to others so that embarrass them. One of participants looked for professional help nearly two years after the violence has passed.

After that, all participants revealed that some coping strategies showed either negative or positive. All participants admitted that they were withdrawing from society and reflecting on sexual violence for many days before deciding to switch on positive coping strategies. One of participants admitted that he tried to escape by drinking alcohol before deciding to seek counselor assistance. Participants revealed that positive coping strategies that they used were providing time for themselves, pursuing their hobbies, and taking time to comply counseling.
Participants revealed that he has been accepted many supports from professional like psychologist or counselor. Furthermore, they suppose that support by those around and expertise are very important for their own condition. According to them, support could come from people around them such as family members and friends, whereas expertise like therapist, doctors, counselors, psychologist, and others. However, the participants revealed that they could not find support while still experiencing sexual violence. This is happened because they are reluctant to open themselves by sharing their experiences regarding sexual violence. The participant appraise that support is needed when deciding to get professional help.

\section{DISCUSSIONS}

Based on the findings of this study, men who experienced sexual violence develop symptoms of stress disorders, depression, isolation, and negative thoughts until now. Those symptoms could be caused by their gender status that raises stereoype about masculinity in our society. Men, in our society, seen as superior figure identified with physical strength, free will, power, and other manly qualities.

Even, one subject tried to commit suicide by drinking chemical liquid excessively. This showed that as men, sexual violence had hurt their ego and self-worth. Struggling to overcome these kind of traumatic experiences make the victims able to do harm and endannger behavior. These are triggered by guilty feeling and lowered gender status as men.

Responses of people around them that are not good would make their suffering is getting worse. There are no awareness from general public and society about this issue. Stigma related to masculinity makes the condition of victims even worse. Considering this 
aspect, future studies may conducting about dynamics of sexual violence perpetrators as well as the used of cognitive interview and investigation techniques.

However, they still struggle to coping their negative feeling and suffering caused by sexual violence. Facing and feeling burden about their condition, they need supporting people around them. This is because they feel that they could not bear the problems by themselves. In their opinion, professional help is the significant supporting stuff that help them to deal wih problems. Support from family, friends, and close people around them are necessary to empower themselves after suffering.

Support from everybody near them and every party who concern with the issue of sexual violence. Support is seen as significant source of encouragement to overcome and develop a good condition to their healing. Supports that they need could be a genuine acceptance about their condition, help them to discuss professional assistance they need, provide support to access professional services, encourage them both moral and mental, and so forth.

\section{CONCLUSIONS}

Sexual violence towards men is a major problem which is often overlooked in researches. Men could be a victim of sexual violence in variety of settings, such as home, workplace, educational institutions, streets, even at prisons. Sexual violence experienced by men that are perpetrated by their female partners leaves physical, mental,emotional, and social suffering to the victim which greater than women.

Men who experienced sexual violence claimed that they have stress disorder, depression, isolation and withdrawal behavior. They also tend to be develop negative self-image and thoughts about themselves. As an adult, negative judgments related sexual experiences has arisen. Gender status become one of issues that disputed among society.

Negative views among society resulted loss of confidence, anger, disappointment, fear, and self-blame by male victims. Almost all of subjects had thought of suicidal ideation. They think that they was fail as men who should have control and power over women. They think that should be able to prevent the occurrence of sexual violence.

Their condition related to sexual violence that they experienced, make they need genuine and huge support from people around them. Survivors of sexual violence need supportive environment, particularly among government and professional that concern in this issue. Generally, survivors believe that experts in judicial area, education, health, and victim protection are having the same role as soicety among them.

Therefore, it becomes inportant to family, friends, professional, society, even everyone surrounding survivors to be more sensitive about their condition. In addition, an understanding of sexual violence perpetrated by both other and same gender is also important for us. Thus, a picture of the occurrence of sexual violence towards men would be clear. Beside that, limitations of this study were using purposissive and nonrandom sampling techniques, so it would be difficult to generalize for all men. 


\section{REFERENCES}

Bergman, M.E., Langhout, R.D., Palmieri, P.A., Cortina,, L.M., \& Fitzgerald, L.F. (2002). The (un)reasonableness of reporting: Antecendents and consequences of reporting sexual harassment. Journal of Applied Psychology, 87, 230-242.

Holzbauer, J.J., \& Conrad, C.F. (2010). A typology of disability harassment in secondary schools. Career Development for Exceptional Individuals, 33(3), 143-154.

Kenny, K., Samah, A.A., \& Fah, B.C.Y. (2011). Sexual harassment: Is it a case of gendered perspective? International Journal of Humanities and Social Science, 1(19), 295-301.

Komnas Perempuan, Komisi Nasional Anti Kekerasan Terhadap Perempuan. (2019). Lembar fakta dan poin kunci catatan tahunan komnas perempuan 2019. Retrieved from http://www.komnasperempuan.go .id/read-news-siaran-pers-catatantahunan-catahu-komnasperempuan-2019

Loxton, D., Dolja-Gore, X., Anderson, A.E., \& Townsend, N. (2017). Intimate partner violence adversely impacts health over 16 years and across generations: A longitudinal cohort study. PoS ONE, 12(6). Retrieved from https://doi.org/10.1371/journal.po ne.0178138.

Mahugu, M.W., Khamasi, J.W., Ktainge, K., Were, G., Karei, R., Daudi, F., \& Kiplagat, H. (2013). Reversed roles? Sexual harassment of male students by female colleagues. Journal of Afrikan Studies in Educational
Management and Leadership, 2(2), 23-38.

Van Niekerk, R.I., \& Ryzgula, R. (2010). The perceptions and occurrence of sexual haarassment aamong male student athletes with male coaches. African Journal for Physical, Health, Education, Recreation and Dance, 6, 49-62.

Weiss, K. (2010). Male sexual victimization: Examining men's experience of rape and sexual assault. Men and Masculinities, 12, 275-298. 